\title{
Positive Finding
}

National Cancer Institute

\section{Source}

National Cancer Institute. Positive Finding. NCI Thesaurus. Code C38758.

A finding of abnormality following an examination or observation confirming something, such as the presence of a disease, condition, or microorganism. 